\title{
Association of Antenatal Care Visit with Utilization of Institutional Delivery Care Services in Afghanistan: Intersections Between Education, Wealth, and Household Decision-Making Autonomy
}

Mostafizur Rahman ( $\square$ mostafizur.r@hotmail.com )

Bangabandhu Sheikh Mujibur Rahman Aviation and Aerospace University

Priom Saha

University of Dhaka

Jalal Uddin

University of Alabama at Birmingham

\section{Research Article}

Keywords: Maternal health, antenatal care (ANC) visit, institutional delivery care service, delivery at a health facility, delivery assisted by a skilled birth attendant

Posted Date: December 20th, 2021

DOI: https://doi.org/10.21203/rs.3.rs-1144471/v1

License: (c) (i) This work is licensed under a Creative Commons Attribution 4.0 International License. Read Full License 


\section{Abstract}

Background: The importance of antenatal visits in safe motherhood and childbirth is well documented. However, less is known how social determinants of health interact with antenatal care (ANC) visits in shaping the uptake of professional delivery care services in low-income countries. This study examines the association of ANC visits with institutional delivery care utilization outcomes in Afghanistan. Further, we assess the extent to which ANC visits intersect with education, wealth, and household decision-making autonomy in predicting two outcomes of delivery care utilization- delivery at a health facility and delivery assisted by a skilled birth attendant.

Methods: We used data from the Afghanistan Demographic and Health Survey (AfDHS) 2015. The analytic sample included 15,581 women of reproductive age (15-49). We assessed the associations using logistic regression models, estimated the predicted probability of delivery care outcomes using statistical interactions, and presented estimates in margins plot.

Results: Regression analyses adjusted for socioeconomic and demographic covariates suggest that women who had 4 or more ANC visits were 5.7 times $(95 \% \mathrm{Cl}=4.78,7.11, \mathrm{P}<0.001)$ more likely to use delivery care at a health facility and 6.5 times $(95 \% \mathrm{Cl}=5.23,8.03 ; \mathrm{P}<0.001)$ more likely to have a delivery assisted by a skilled birth attendant compared to women who had no ANC visit. Estimates from models with statistical interactions between ANC, education, wealth, and decision-making autonomy suggest that women with higher social status were more advantageous in utilizing institutional delivery care services compared to women with lower levels of social status.

Conclusion: Our findings suggest that the association of ANC visit with institutional delivery care services is stronger among women with higher social status. The results have implications for promoting safe motherhood and childbirth through improving women's social status.

\section{Introduction}

Sustainable Development Goal (SDG) 3.1 aims at reducing maternal mortality to 70 deaths per 100,000 live births by 2030 [1]. Worldwide, 295,000 women (or 211 per 100,000) died due to pregnancy-related complications in 2017. More specifically, 810 women died every day in 2017 and 94 percent of these deaths occurred in low and lower-middleincome settings. In Afghanistan, the maternal mortality rate prevails at 638 per 100,000 live births [2], which is far from achieving the SDG target. In reducing maternal mortality, World Health Organization [3] advocated that delivery at a health facility and delivery assisted by a skilled birth attendant are the foremost priorities.

Antenatal care (ANC) visits during pregnancy can significantly promote the continuation of institutional care for safe childbirth and postnatal care. Higher ANC visits can reduce the number of deaths by preventing pregnancy-related complications [2, 4]. Conversely, lower ANC visits and utilization increase the risk of maternal mortality by double [5]. The uptake of ANC services remains substantially low in Afghanistan, where only about 21 percent of women used four or more ANC visits in 2017 [6].

Socioeconomic status (SES) is a significant predictor of institutional maternity care services. One's socioeconomic status raises awareness of seeking safer maternity care and provides the resource base necessary for uptaking institutional care $[7,8]$. Recent data from Afghanistan suggest that SES indicators, including mother's education, wealth, and urbanity cluster, significantly shape ANC services. For instance, 41 percent of women who delivered at home were mostly from rural, lower wealth, and lower levels of education. The births were either attended by a friend, neighbor, relative, or traditional birth attendant. On the contrary, women receiving delivery care assisted by a skilled birth attendant mainly were from urban and upper social stratum [6]. Likewise, several studies have found that SES, 
including wealth, education, residence, and decision-making autonomy, were significant predictors of the uptake of the institutional delivery care services and having birth assisted by a skilled birth attendant in Afghanistan [9-13].

Existing studies focusing on socioeconomic disparities in institutional delivery care services employ a unidimensional and additive approach, which implies that social status and structural factors are mutually separate and are additive determinants of social disparity in health services utilization [14-17]. With an additive analytic approach, these studies fail to grasp the intersecting nature of social status and structural elements. Conversely, intersectionality literature has shown that social status indicators may intersect with one another and produce unique social (dis)advantage and opportunity [18-20]. In opposition to the additive approach, the intersectionality perspective demonstrates how social identity, social position, cultural norms, geography, and opportunities can have interlocking and mutually reinforcing effects on health services utilization [21].

In line with the intersectionality perspective, we hypothesize that women with lower education, lower wealth, and diminished autonomy in household decision-making constitute a population group having 'multiple jeopardies' or 'disadvantages' [22, 23]. More specifically, multiple social disadvantages, including poorer wealth base, education, autonomy, and regional contexts, may intersect with one another to produce inequality in necessary health services utilization. Although the intersectionality approach has been widely used in population health studies, mostly in the context of industrially-developed countries, this approach has rarely been used in health services research in lowincome settings. An investigation of examining the inequality in health services research using an intersectionality perspective has implications for informing interventions and public health programs aiming to improve maternal and child health in low-income countries. Applying an intersectionality perspective in health services research and leveraging the first demographic and health survey of Afghanistan, we examined the intersecting effects of ANC visits, women's education, household wealth, and household decision-making autonomy on two outcomes of institutional delivery care services utilization in Afghanistan - delivery at a health facility and delivery assisted by a skilled birth attendant.

\section{Data And Methods}

\section{Data}

We analyzed de-identified data from the 2015 Afghanistan Demographic and Health Survey (AfDHS). AfDHS is a nationally-representative cross-sectional household survey, which used a two-stage stratified sampling technique to collect data on nutrition, mortality, fertility, maternal, and reproductive health of ever-married women. For the survey, 25,741 households were initially selected, and 24,395 of them were finally interviewed. The response rate was $98 \%$. Data were collected between June 15, 2015 and February 23, 2016. Data entry was done twice for 100\% accuracy and verification. The AfDHS survey sought informed consent from each respondent. In this study, the analysis was limited to the most recent singleton live birth. After excluding observations with missing values, the final analytic sample included 15,581 women aged between 15 and 49 years.

\section{Outcome variables}

The analysis included two binary outcomes in this paper - delivery at a health facility and delivery assisted by a skilled birth attendant. Delivery at a health facility was coded 1 if the delivery took place at a health facility (e.g., government or private hospital/health center/health post, maternal and child welfare center, NGO static clinic, and sub-district health center) and 0 if delivery was at home. Likewise, delivery assisted by a skilled birth attendant was 
coded 1 if a skilled birth attendee assisted the delivery (e.g., doctor, nurse, community skilled birth attendant, family welfare visitor, and midwife) and 0 otherwise.

\section{Key explanatory variables}

ANC visit: The key exposure variable in the analysis was ANC visits during pregnancy. Women were asked about the number of their ANC visits during pregnancy. The response was continuous and ranged between 0 and 20 . The following categories were used in the analysis: $0,1,2,3$, and $\geq 4$ ANC visits.

Covariates: The analysis adjusted for women's demographic factors, socioeconomic factors, and women's autonomy index. Demographic variables included women's current age (in years) and place of residence (rural/urban).

Socioeconomic variables included education (in years), wealth index, and employment (occupied/not occupied), while other covariates were decision-making autonomy and wife beating not justified.

Wealth index: Wealth index is a measure of a cumulative living standard of a household. This index consists of the household's possession of various household assets, dwelling characteristics, and farm characteristics. For instance, assets and dwelling characteristics include radio, television, bicycles, mobile phones, computers, refrigerators, housing construction materials, furniture, farm animals, agricultural land, sanitation facilities, water access, etc. Using the principle component analysis, households were assigned scores based on their ownership of type and amount of the above assets and household items. Finally, a continuous asset score was assigned to each household, and then they were categorized into five wealth quintiles [24].

Decision-making autonomy index: Decision-making autonomy index was a composite measure of three household decision-making questions, including a) "Person who usually decides on respondent's health care", b) "Person who usually decides on large household purchases", and c) "Person who usually decides on visits to family or relatives". For this index, the response "respondent alone" was coded 2, "respondent and husband/partner" was coded 1, and other responses such as "respondent and other person", "husband/partner alone", and "someone else" were coded 0. The summed score of three items ranged from 0 to 6 , where a higher score referred to women's higher autonomy in the household decision-making process.

Wife beating not justified index: Wife beating not justified index was a summative index composed of the following five items representing women's perception about violence perpetrated by their husbands/partners against them: a) "Beating justified if wife goes out without telling husband", b) "Beating justified if wife neglects the children", c) "Beating justified if wife argues with husband", d) "Beating justified if wife refuses to have sex with husband", and e) "Beating justified if wife burns the food". The response "no" for all items was coded 0, and the response "yes" was coded 1, while the response "don't know" was coded missing. Then, the scores of all items were summed, and the total score ranged between 0 and 5 , where score 0 indicated beating not justified, and score 1-5 indicated that women perceived the beating as justified.

\section{Statistical analyses}

In the beginning, we presented sample characteristics of the respondents. Then, we assessed the associations between ANC visits and two outcomes, using logistic regression analysis adjusting for the potential covariates. In regression analysis, we estimated three models. In the first model, we minimally adjusted for respondents' age and place of residence. The second model further adjusted for socioeconomic factors, including education (in years), 
wealth index, and employment status. In the third model, we further adjusted for women's household decision-making autonomy and beating not justified in addition to the covariates adjusted in the second model. We estimated model fit statistics using AIC (Akaike information criterion) and BIC (Bayesian information criterion). The model with minimum $\mathrm{AIC}$ and BIC values was selected for final regression. The regression analysis also incorporated complex survey design factors, including survey strata, clusters, and weights.

Finally, the intersecting effects of ANC visits with SES factors and household decision-making autonomy were examined using a series of two-way and three-way statistical interactions. We used Stata's margins command (at means) to compute adjusted predicted probabilities from the models with interactions for ease of interpretation. We presented the adjusted predicted probabilities in Figures 1-4. Stata 15.1 (Stata Corp LP, College Station, TX) was used for all data analyses.

\section{Results}

Table 1 shows the characteristics of the study sample by antenatal care (ANC) visits in Afghanistan. Among the women with 4 or more ANC visits, only $12 \%$ were from the lowest wealth quintile, and $29 \%$ were from the richest wealth quintile. Women with the highest years of education (2.53) had higher ANC visits (4 or more) compared to lowest-educated women (0.53) with no ANC visit. Average age of the respondent was 29 years across categories of ANC visit. Women had higher decision-making autonomy scores in $\geq 4$ ANC visit category than other ANC visit categories. For instance, the average decision-making autonomy score was 1.27 for women with no ANC visits and 1.87 for women with 4 or more ANC visits. Rural women tend to have lower number of ANC visits. For example, of the women with no ANC visits, $82 \%$ resides in rural area. Contrarily, $58 \%$ of the women with 4 or more ANC visits are urban residents. 
Table 1

Sample characteristics of women by ANC visit ( $N=15581)$.

Antenatal Care (ANC) visits

$\chi^{2} / F$ statistic ( $P$ value)

$\begin{array}{lllllll}\text { Variables, } \%(\mathrm{~N}) & 0 \text { Visit } & 1 \text { Visit } & 2 \text { Visits } & 3 \text { Visits } & \underset{\text { visits }}{\geq 4} & \text { Total }\end{array}$

Wealth Index

\begin{tabular}{|c|c|c|c|c|c|c|c|}
\hline Poorest & $\begin{array}{l}0.21 \\
(1421)\end{array}$ & $\begin{array}{l}0.19 \\
(319)\end{array}$ & $\begin{array}{l}0.19 \\
(490)\end{array}$ & $\begin{array}{l}0.19 \\
(342)\end{array}$ & $\begin{array}{l}0.12 \\
(334)\end{array}$ & $\begin{array}{l}0.19 \\
(2906)\end{array}$ & \multirow[t]{5}{*}{$\begin{array}{l}847.94 \\
(<0.01)\end{array}$} \\
\hline Poorer & $\begin{array}{l}0.27 \\
(1825)\end{array}$ & $\begin{array}{l}0.24 \\
(407)\end{array}$ & $\begin{array}{l}0.21 \\
(558)\end{array}$ & $\begin{array}{l}0.18 \\
(312)\end{array}$ & $\begin{array}{l}0.14 \\
(369)\end{array}$ & $\begin{array}{l}0.22 \\
(3471)\end{array}$ & \\
\hline Middle & $\begin{array}{l}0.24 \\
(1600)\end{array}$ & $\begin{array}{l}0.24 \\
(420)\end{array}$ & $\begin{array}{l}0.22 \\
(584)\end{array}$ & $\begin{array}{l}0.20 \\
(351)\end{array}$ & $\begin{array}{l}0.20 \\
(523)\end{array}$ & $\begin{array}{l}0.22 \\
(3478)\end{array}$ & \\
\hline Richer & $\begin{array}{l}0.19 \\
(1303)\end{array}$ & $\begin{array}{l}0.22 \\
(370)\end{array}$ & $\begin{array}{l}0.24 \\
(627)\end{array}$ & $\begin{array}{l}0.25 \\
(442)\end{array}$ & $\begin{array}{l}0.25 \\
(671)\end{array}$ & $\begin{array}{l}0.22 \\
(3413)\end{array}$ & \\
\hline Richest & $\begin{array}{l}0.09 \\
(639)\end{array}$ & $\begin{array}{l}0.12 \\
(205)\end{array}$ & $\begin{array}{l}0.14 \\
(365)\end{array}$ & $\begin{array}{l}0.19 \\
(332)\end{array}$ & $\begin{array}{l}0.29 \\
(781)\end{array}$ & $\begin{array}{l}0.15 \\
(2322)\end{array}$ & \\
\hline $\begin{array}{l}\text { Education (in years), mean } \\
\text { (SD) }\end{array}$ & $\begin{array}{l}0.53 \\
(0.02)\end{array}$ & $\begin{array}{l}0.85 \\
(0.06)\end{array}$ & $\begin{array}{l}1.19 \\
(0.06)\end{array}$ & $\begin{array}{l}1.70 \\
(0.08)\end{array}$ & $\begin{array}{l}2.53 \\
(0.07)\end{array}$ & $\begin{array}{l}1.14 \\
(0.02)\end{array}$ & $\begin{array}{l}970.28 \\
(<0.01)\end{array}$ \\
\hline Age (in years), mean (SD) & $\begin{array}{l}29.00 \\
(0.08)\end{array}$ & $\begin{array}{l}28.93 \\
(0.16)\end{array}$ & $\begin{array}{l}28.53 \\
(0.13)\end{array}$ & $\begin{array}{l}28.86 \\
(0.16)\end{array}$ & $\begin{array}{l}28.78 \\
(0.13)\end{array}$ & $\begin{array}{l}28.89 \\
(0.05)\end{array}$ & $\begin{array}{l}3.00 \\
(0.0173)\end{array}$ \\
\hline $\begin{array}{l}\text { Decision-making } \\
\text { autonomy, mean (SD) }\end{array}$ & $\begin{array}{l}1.27 \\
(0.01)\end{array}$ & $\begin{array}{l}1.31 \\
(0.03)\end{array}$ & $\begin{array}{l}1.46 \\
(0.03)\end{array}$ & $\begin{array}{l}1.60 \\
(0.03)\end{array}$ & $\begin{array}{l}1.87 \\
(0.03)\end{array}$ & $\begin{array}{l}1.50 \\
(0.01)\end{array}$ & $\begin{array}{l}91.88 \\
(<0.01)\end{array}$ \\
\hline Occupation & & & & & & & \\
\hline Not occupied & $\begin{array}{l}0.83 \\
(5664)\end{array}$ & $\begin{array}{l}0.87 \\
(1496)\end{array}$ & $\begin{array}{l}0.90 \\
(2367)\end{array}$ & $\begin{array}{l}0.90 \\
(1595)\end{array}$ & $\begin{array}{l}0.90 \\
(2420)\end{array}$ & $\begin{array}{l}0.86 \\
(13545)\end{array}$ & 136.31 \\
\hline Occupied & $\begin{array}{l}0.17 \\
(1124)\end{array}$ & $\begin{array}{l}0.13 \\
(225)\end{array}$ & $\begin{array}{l}0.10 \\
(257)\end{array}$ & $\begin{array}{l}0.10 \\
(184)\end{array}$ & $\begin{array}{l}0.10 \\
(258)\end{array}$ & $\begin{array}{l}0.14 \\
(2048)\end{array}$ & \\
\hline
\end{tabular}

Place of residence

\begin{tabular}{llllllll} 
Urban & 0.18 & 0.21 & 0.17 & 0.27 & 0.42 & 0.24 & 725.28 \\
& $(1068)$ & $(383)$ & $(459)$ & $(538)$ & $(1242)$ & $(3690)$ & $(<0.001)$ \\
\cline { 1 - 1 } & & & & & \\
& 0.82 & 0.79 & 0.83 & 0.73 & 0.58 & 0.76 & \\
& $(4775)$ & $(1448)$ & $(2276)$ & $(1462)$ & $(1732)$ & $(12000)$ &
\end{tabular}

Beating Not Justified

Note: Chi-square for categorical and F-statistic for continuous variables. 


\begin{tabular}{|c|c|c|c|c|c|c|c|}
\hline \multirow[b]{2}{*}{ Variables, \% (N) } & \multicolumn{6}{|c|}{ Antenatal Care (ANC) visits } & \multirow{2}{*}{$\begin{array}{l}\chi^{2} / F \text { statistic ( } P \\
\text { value) }\end{array}$} \\
\hline & 0 Visit & 1 Visit & 2 Visits & 3 Visits & $\begin{array}{l}\geq 4 \\
\text { visits }\end{array}$ & Total & \\
\hline Justified & $\begin{array}{l}0.83 \\
(5654)\end{array}$ & $\begin{array}{l}0.84 \\
(1453)\end{array}$ & $\begin{array}{l}0.86 \\
(2249)\end{array}$ & $\begin{array}{l}0.87 \\
(1547)\end{array}$ & $\begin{array}{l}0.79 \\
(2340)\end{array}$ & $\begin{array}{l}0.84 \\
(13059)\end{array}$ & \multirow[t]{2}{*}{$\begin{array}{l}43.19 \\
(<0.001)\end{array}$} \\
\hline Not Justified & $\begin{array}{l}0.17 \\
(1134)\end{array}$ & $\begin{array}{l}0.16 \\
(268)\end{array}$ & $\begin{array}{l}0.14 \\
(375)\end{array}$ & $\begin{array}{l}0.13 \\
(232)\end{array}$ & $\begin{array}{l}0.20 \\
(522)\end{array}$ & $\begin{array}{l}0.16 \\
(2531)\end{array}$ & \\
\hline Total & $\begin{array}{l}6788 \\
(43.50)\end{array}$ & $\begin{array}{l}1721 \\
(11.04)\end{array}$ & $\begin{array}{l}2624 \\
(16.83)\end{array}$ & $\begin{array}{l}1779 \\
(11.41)\end{array}$ & $\begin{array}{l}2678 \\
(17.18)\end{array}$ & 15590 & \\
\hline
\end{tabular}

Table 2 reports distribution of delivery at a health facility, and delivery assisted by a skilled birth attendant by ANC visit categories and associated chi-square test results. Nearly $27 \%$ of women with $\geq 4$ ANC visits had a delivery at a health facility and had skilled birth attendant during delivery. The associations of ANC visits with delivery at a health facility and delivery assisted by a skilled birth attendant were significant at $0.001 \%$ level of significance.

Table 2

Chi-square test of ANC visit, delivery at a health facility, and delivery assisted by a skilled birth attendant.

\begin{tabular}{|c|c|c|c|c|}
\hline \multirow{2}{*}{$\begin{array}{l}\text { Number of } \\
\text { ANC visits }\end{array}$} & \multicolumn{2}{|c|}{ Delivery at a health facility } & \multicolumn{2}{|c|}{ Delivery assisted by a skilled birth attendant } \\
\hline & $\%(\mathrm{~N})$ & $x^{2}$ & $\%(N)$ & $x^{2}$ \\
\hline 0 visit & 23.87 (1851) & \multirow[t]{5}{*}{$2700 * *$} & 23.97 (1911) & \multirow[t]{5}{*}{$2900 \star \star$} \\
\hline 1 visit & 11.72 (909) & & 11.69 (932) & \\
\hline 2 visits & 21.50 (1667) & & 24.45 (1710) & \\
\hline 3 visits & 15.97 (1238) & & 15.77 (1257) & \\
\hline$\geq 4$ visits & 26.94 (2089) & & $27.11(2161)$ & \\
\hline$\star * p<0.001$ & & & & \\
\hline
\end{tabular}


Table 3

Adjusted odds ratios and 95\% confidence intervals for institutional delivery care indicators ( $N=15581)$.

\begin{tabular}{|c|c|c|c|c|c|c|}
\hline \multirow[t]{4}{*}{$\begin{array}{l}\text { Number of ANC } \\
\text { visits (Ref: } 0 \text { ) }\end{array}$} & \multicolumn{3}{|c|}{ Delivery at a health facility } & \multicolumn{3}{|c|}{$\begin{array}{l}\text { Delivery assisted by a skilled birth } \\
\text { attendant }\end{array}$} \\
\hline & OR & OR & OR & OR & OR & OR \\
\hline & $(95 \% \mathrm{Cl})$ & $(95 \% \mathrm{Cl})$ & $(95 \% \mathrm{Cl})$ & $(95 \% \mathrm{Cl})$ & $(95 \% \mathrm{Cl})$ & $(95 \% \mathrm{Cl})$ \\
\hline & Model 1 & Model 2 & Model 3 & Model 1 & Model 2 & Model 3 \\
\hline 1 & $\begin{array}{l}2.41^{\star} \\
(1.96,2.97)\end{array}$ & $\begin{array}{l}2.47^{\star} \\
(1.92,3.01)\end{array}$ & $\begin{array}{l}2.45^{\star} \\
(1.96,3.03)\end{array}$ & $\begin{array}{l}2.38^{*} \\
(1.92,2.94)\end{array}$ & $\begin{array}{l}2.39 * \\
(1.92,2.97)\end{array}$ & $\begin{array}{l}2.38^{\star} \\
(1.91,2.97)\end{array}$ \\
\hline 2 & $\begin{array}{l}3.64^{\star} \\
(2.92,4.53)\end{array}$ & $\begin{array}{l}3.61^{\star} \\
(2.93,4.43)\end{array}$ & $\begin{array}{l}3.57^{\star} \\
(2.92,4.37)\end{array}$ & $\begin{array}{l}3.66^{\star} \\
(2.94,4.55)\end{array}$ & $\begin{array}{l}3.61^{\star} \\
(2.93,4.43)\end{array}$ & $\begin{array}{l}3.58^{*} \\
(2.92,4.39)\end{array}$ \\
\hline 3 & $\begin{array}{l}4.11 \star \\
(3.25,5.21)\end{array}$ & $\begin{array}{l}3.88^{*} \\
(3.20,4.77)\end{array}$ & $\begin{array}{l}3.84^{\star} \\
(3.06,4.69)\end{array}$ & $\begin{array}{l}4.07^{\star} \\
(3.21,5.16)\end{array}$ & $\begin{array}{l}3.74 * \\
(3.02,3.65)\end{array}$ & $\begin{array}{l}3.71^{\star} \\
(2.98,4.62)\end{array}$ \\
\hline$\geq 4$ & $\begin{array}{l}7.00 * \\
(5.61,8.75)\end{array}$ & $\begin{array}{l}5.89 * \\
(4.75,7.38)\end{array}$ & $\begin{array}{l}5.74 * \\
(4.78,7.11)\end{array}$ & $\begin{array}{l}7.98^{\star} \\
(6.28,10.06)\end{array}$ & $\begin{array}{l}6.67^{*} \\
(5.33,8.32)\end{array}$ & $\begin{array}{l}6.48^{\star} \\
(5.23,8.03)\end{array}$ \\
\hline $\mathrm{AIC}$ & 18091.88 & 16397.41 & 16364.50 & 17790.89 & 16194.53 & 16136.71 \\
\hline $\mathrm{BIC}$ & 18145.47 & 16596.48 & 16494.60 & 17844.89 & 16309.34 & 16266.83 \\
\hline \multicolumn{7}{|c|}{ *P<0.05; ANC, antenatal care; $\mathrm{Cl}$, confidence interval; OR, odds ratio. } \\
\hline \multicolumn{7}{|c|}{ Model 1: Adjusted for respondents' current age and place of residence. } \\
\hline \multicolumn{7}{|c|}{ Model 2: Further adjusted for education, wealth, and employment status. } \\
\hline
\end{tabular}

Table 3 presents the adjusted odds ratio (OR) with 95\% confidence interval (Cl) from the logistic regression analysis. Controlling for potential covariates in all models, we found that ANC visit was significantly associated with the two outcomes - delivery at a health facility and delivery assisted by a skilled birth attendant. In fully-adjusted model 3, the odds of delivery at a health facility were greater for those who had 4 or more ANC visits $(\mathrm{OR}=5.74,95 \% \mathrm{Cl}=4.78$, 7.11) than those who had no ANC visit. Likewise, the odds of delivery assisted by a skilled birth attendant were higher at higher levels of ANC visit. The odds of having a delivery assisted by a skilled birth attendant were 6.48 (95\% $\mathrm{Cl}=$ $5.23,8.03 ; \mathrm{P}<0.001$ ) for women who had 4 or more ANC visits compared to those who had no ANC visits. Overall, the results suggest that women with higher number of ANC visits had greater odds of having institutional delivery care services.

Figures 1-3 present the adjusted predicted probabilities obtained from a series of two-way interactions between ANC visit, wealth, education, and household decision-making autonomy, with other sociodemographic variables held at their mean. Figure 1 suggests that women who were from the richest wealth quintile had the greatest probability, among all other wealth categories, of having a delivery at a health facility and delivery assisted by a skilled birth attendant at $\geq 4$ ANC visits. Similarly, Figure 2 shows that as the education year increases, the probability of using institutional delivery care services (delivery at a health facility and delivery assisted by a skilled birth attendant) increases significantly for the women who have $\geq 4$ ANC visits. Finally, Figure 3 suggests that among women with $\geq 4$ ANC visits, the higher the decision-making autonomy, the higher was the probability of institutional delivery care utilization- delivery at a health facility and delivery assisted by a skilled birth attendant. 
Figure 4 presents the differential effect of ANC visits by years of education and wealth index with other sociodemographic variables held at their mean. The effect of ANC visits on using institutional delivery care services was generally higher among women in wealthier categories and those with higher years of education. Further, wealth quintile differences in the effect ANC visit tend to diverge at the lower levels of education and converge or attenuate at the highest levels.

\section{Discussion}

ANC visit has been highlighted as an important parameter of improving the utilization of maternal health care. Given the importance of SES factors, many studies assessed the association of ANC visits with delivery at a health facility and delivery assisted by a skilled birth attendant using unidimensional or additive approaches, where the intersectional effects of ANC and socioeconomic status were entirely absent. In this study, we found robust evidence that ANC visit intersects with SES indicators, including wealth and education and impact the delivery care utilization in Afghanistan.

Our analysis finds that ANC is an important and significant predictor of delivery at a health facility. The results suggest that women who had four or more ANC visits were more likely to have a delivery at a health facility. Similarly, previous studies also found a positive relationship between ANC visits and delivery at a health facility $[16,17]$. For instance, Berhan \& Berhan [4] and Dahiru \& Oche [15] reported that women who received at least four ANC visits were respectively 7 and 2 times more likely to have a delivery at a health facility, while our study found that women who received at least four ANC visits were over 5 times likely to have childbirth at a health facility.

The analysis demonstrated that ANC visit is also a strong predictor of delivery assisted by a skilled birth attendant. More specifically, four or more ANC visits were associated with increased utilization of a delivery assisted by a skilled birth attendee. A plausible mechanism underlying this association is that women with higher number of ANC visits have higher awareness of the pregnancy-related complications, and thus they are more likely to seek professional delivery care services $[25,26]$. So, the women who have more ANC visits at a health facility have more chances to meet skilled birth personnel and thus to have delivery there by them. Similar to our findings, prior studies have shown that having a birth assisted by a professional birth attendee is more pronounced among women who had four or more ANC visits [27-30].

It is well documented that SES indicators such as education, income, and wealth significantly shape the utilization of maternity care outcomes such as having a birth at a health care center $[8,15,31]$ and having a delivery assisted by a skilled birth attendant [28, 29, 32-34]. Similar to the prior studies, this analysis found significant impacts of SES factors on the uptake of delivery care services among reproductive-aged women. More specifically, our analysis suggests that women from socially advantaged groups (e.g., those with higher education, wealth, and autonomy) were more likely to utilize institutional delivery care services. It is well-known that women from higher SES are better equipped with financial and health-enhancing resources to utilize necessary services for maternity care. Broadly, women from higher social status groups are well aware, knowledgeable, health-conscious, and financially able to meet health expenditures compared to those who are from lower SES [7, 35].

In line with the intersectionality perspective, our analysis has demonstrated that differential effects of ANC jointly varies by two significant SES factors - wealth index and years of education. Broadly, predicted probabilities, derived from the interaction models, suggest that women with higher education, wealth, and autonomy are more likely to have a delivery at a health facility and delivery assisted by a skilled birth attendant. As explained by intersectionality scholars, women with higher education and greater family wealth, and increased power in the household have 
multiplicative advantages and opportunities at their disposal $[22,23]$. Women's higher social standing allows them to maintain the continuity of care by establishing a usual source of care [36,37]. Likewise, a number of intersectionality studies found similar associations between ANC visit and delivery care utilization in low-income settings [38-40]. Other studies also significantly documented that SES factors including wealth [14, 16, 41, 42], autonomy [43-45], and education $[31,45,46]$ have positive effects on utilization of delivery care services. Further, our analysis indicates that predicted estimates of the associations of ANC visits with delivery care outcomes tend be heterogeneous at the lower levels of education and converge or attenuate at the highest levels. Such findings point to the possibility that consequences of having multiple disadvantages put women at increased risk of not having professional maternity care services. In other words, most advantaged sections of the women tend to have better protective benefit from their relative social status.

\section{Strengths, limitations, and future researches}

One of the strengths of this study is that it uses a nationally representative survey and can thus be inferred to the national level. We applied an intersectionality perspective, which addresses the limitation of studies that typically use an additive or unidimensional approach. In this regard, an intersectionality framework can be useful in documenting how ANC visits and various SES indicators complexly intersect to shape the uptake of delivery care services in a lowincome setting. Despite these strengths, we acknowledge a few notable limitations. The data on delivery care utilization was based on self-report of the respondents, and responses might be subject to long-recall bias and social desirability issues. To minimize the bias in our outcome variables, we limited the analysis to the last singleton live birth in the last year preceding the survey. Further, despite controlling for several potential confounding factors, we were unable to control for some other relevant confounders such as husband's SES, women's social network, and financial and physical access to health care centers. While existing researches generally emphasize on the role of socioeconomic and demographic determinants of maternity care utilization, other predictors including information, knowledge, awareness, perceived benefits, barriers, and physical access factors largely remain absent in quantitative analysis. We note that future studies may explore the role of these factors in maternity care research in a low-income setting.

\section{Conclusion}

Our analysis suggests that four or more ANC visits are significantly associated with increased institutional delivery care utilization. Further, ANC visits complexly intersect with SES indicators to predict institutional delivery care services utilization such that women from the upper social stratum enjoy multiple advantages in uptaking those services. Our findings have implications for informing interventions and targeted public health programs aiming to reduce social disparities in professional delivery care services in low-income countries.

\section{Declarations}

\section{Ethics approval and consent to participate}

Demographic and Health Survey (DHS) is approved by the Internal Review Board of ICF International (USA) and by relevant country authorities. DHS collects informed consent from the participants and do not permit the respondents or households to be identified. Before accessing data from webpage, an approval was sought from MEASURE DHS upon having electronic registration and exposing plan for data and analysis. All methods in accordance with the Declaration of Helsinki were carried out. 


\section{Consent for publication}

Not applicable.

\section{Availability of data and materials}

Data are available online and one can access from https://dhsprogram.com.

\section{Competing interests}

None.

\section{Funding}

None.

\section{Authors' contributions}

MR and JU conceptualized the study and modeled analysis. JU and PS analyzed the data. PS interpreted analysis, and MR prepared the first draft. All authors reviewed the draft and permitted final manuscript.

\section{Acknowledgements}

We acknowledge MEASURE DHS for providing Demographic and Health Survey data.

\section{References}

1. United Nations. Global indicator framework for the Sustainable Development Goals and targets of the 2030 Agenda for Sustainable Development Goals and targets Indicators. United Nations Statistics Division: New York, NY, USA. 2017.

https://unstats.un.org/sdgs/indicators/Global\%20Indicator\%20Framework\%20after\%202020\%20review_Eng.pdf.

2. WHO, UNFPA, UNICEF, World Bank Group, United Nations Population Division. Maternal mortality: level and trends 2000 to 2017. Sexual and Reproductive Health. Geneva. 2019;1-104. https://www.who.int/reproductivehealth/publications/maternal-mortality-2000-2017/en/.

3. World Health Organization. Standards for improving quality of maternal and newborn care in health facilities. Geneva. 2016; 1-73. https://cdn.who.int/media/docs/default-source/mca-documents/advisory-groups/qualityof-care/standards-for-improving-quality-of-maternal-and-newborn-care-in-health-facilities.pdf?sfvrsn=3b364d8_2.

4. Berhan Y, Berhan A. Antenatal care as a means of increasing birth in the health facility and reducing maternal mortality: a systematic review. Ethiopian journal of health sciences. 2014 Sep 12; 24: 93-104.

5. Bauserman M, Lokangaka A, Thorsten V, Tshefu A, Goudar SS, Esamai F, et al. Risk factors for maternal death and trends in maternal mortality in low- and middle-income countries: A prospective longitudinal cohort analysis. Reproductive Health. 2015 Dec; 12(2):1-9. 
6. Afghanistan Health Survey. Afghanistan Health Survey 2018. Kabul, Afghanistan; 2019: 1-121. https://www.kit.nl/wp-content/uploads/2019/07/AHS-2018-report-FINAL-15-4-2019.pdf.

7. Wardle J, Steptoe A. Socioeconomic differences in attitudes and beliefs about healthy lifestyles. J Epidemiol Community Health. 2003 Jun 1; 57 (6):440-3.

8. Fagbamigbe AF, Idemudia ES. Wealth and antenatal care utilization in Nigeria: Policy implications. Health Care Women Int. 2017 Jan 2; 38(1):17-37.

9. Akseer N, Bhatti Z, Rizvi A, Salehi AS, Mashal T, Bhutta ZA. Coverage and inequalities in maternal and child health interventions in Afghanistan. BMC Public Health. 2016 Sep; 16(2): 119-37.

10. Azimi MD, Najafizada SAM, Khaing IK, Hamajima N. Factors influencing non-institutional deliveries in Afghanistan: Secondary analysis of the Afghanistan Mortality Survey 2010. Nagoya J Med Sci. 2015 Feb; 77(12):133.

11. Kim C, Saeed KMA, Salehi AS, Zeng W. An equity analysis of utilization of health services in Afghanistan using a national household survey. BMC Public Health. 2016 Dec; 16(1):1-11.

12. Mumtaz S, Bahk J, Khang YH. Current status and determinants of maternal healthcare utilization in Afghanistan: Analysis from Afghanistan demographic and health survey 2015. PLoS One. 2019 Jun 11; 14(6):e0217827.

13. Shahram MS, Hamajima N, Reyer JA. Factors affecting maternal healthcare utilization in Afghanistan: Secondary analysis of Afghanistan Health Survey 2012. Nagoya J Med Sci. 2015 Nov; 77(4):595.

14. Afulani PA, Moyer C. Explaining disparities in use of skilled birth attendants in developing countries: A conceptual framework. PLoS One. 2016 Apr 22; 11(4):e0154110.

15. Dahiru T, Oche OM. Determinants of antenatal care, institutional delivery and postnatal care services utilization in Nigeria. Pan Afr Med J. 2015; 22(1).

16. Gabrysch S, Campbell OMR. Still too far to walk: Literature review of the determinants of delivery service use. BMC Pregnancy Childbirth. 2009 Dec; 9(1):1-8.

17. Ryan BL, Krishnan RJ, Terry A, Thind A. Do four or more antenatal care visits increase skilled birth attendant use and institutional delivery in Bangladesh? A propensity-score matched analysis. BMC Public Health. 2019 Dec; 19(1):1-6.

18. Bauer GR. Incorporating intersectionality theory into population health research methodology: Challenges and the potential to advance health equity. Soc Sci Med. 2014 Jun 1; 110:10-7.

19. Brown TH, Richardson LJ, Hargrove TW, Thomas CS. Using Multiple-hierarchy Stratification and Life Course Approaches to Understand Health Inequalities: The Intersecting Consequences of Race, Gender, SES, and Age. J Health Soc Behav. 2016 Jun; 57(2):200-22.

20. Cummings JL, Jackson PB. Race, gender, and SES disparities in self-assessed health, 1974-2004. Res Aging. 2008 Mar; 30(2):137-67.

21. Kapilashrami A, Hankivsky O. Intersectionality and why it matters to global health. The Lancet. 2018 Jun 30; 391(10140):2589-91.

22. King DK. Multiple Jeopardy, Multiple Consciousness: The Context of a Black Feminist Ideology. Signs J Women Cult Soc. 1988 Oct 1; 14(1):42-72.

23. Veenstra G. Race, gender, class, and sexual orientation: Intersecting axes of inequality and self-rated health in Canada. Int J Equity Health. 2011 Dec; 10(1):1-11.

24. Rutstein SO, Johnson K. The DHS Wealth Index, DHS Comparative Report 6. Calverton, Maryland, USA: ORC Macro. 2004. doi: 10.13140/2.1.2806.4809. 
25. Rajbanshi S, Norhayati MN, Nik Hazlina NH. Perceptions of good-quality antenatal care and birthing services among postpartum women in Nepal. Int J Environ Res Public Health. 2021 Jan; 18(13):6876.

26. Jallow IK, Chou YJ, Liu TL, Huang N. Women's perception of antenatal care services in public and private clinics in the Gambia. Int J Qual Heal Care. 2012 Dec 1; 24(6):595-600.

27. Anastasi E, Borchert M, Campbell OMR, Sondorp E, Kaducu F, Hill O, et al. Losing women along the path to safe motherhood: Why is there such a gap between women's use of antenatal care and skilled birth attendance? A mixed methods study in northern Uganda. BMC Pregnancy Childbirth. 2015 Dec; 15(1):1-5.

28. Choulagai B, Onta S, Subedi N, Mehata S, Bhandari GP, Poudyal A, et al. Barriers to using skilled birth attendants' services in mid- and far-western Nepal: A cross-sectional study. BMC Int Health Hum Rights. 2013 Dec; 13(1):1-9.

29. Kibria GM Al, Ghosh S, Hossen S, Barsha RAA, Sharmeen A, Uddin SMI. Factors affecting deliveries attended by skilled birth attendants in Bangladesh. Matern Heal Neonatol Perinatol. 2017 Dec; 3(1):1-9.

30. Mengesha ZB, Biks GA, Ayele TA, Tessema GA, Koye DN. Determinants of skilled attendance for delivery in Northwest Ethiopia: A community based nested case control study. BMC Public Health. 2013 Dec; 13(1):1-6.

31. Doctor H V., Nkhana-Salimu S, Abdulsalam-Anibilowo M. Health facility delivery in sub-Saharan Africa: Successes, challenges, and implications for the 2030 development agenda. BMC Public Health. 2018 Dec; 18(1):1-12.

32. Adewemimo AW, Msuya SE, Olaniyan CT, Adegoke AA. Utilisation of skilled birth attendance in Northern Nigeria: A cross-sectional survey. Midwifery. 2014 Jan 1; 30(1):e7-13.

33. Pulok MH, Sabah MNU, Uddin J, Enemark U. Progress in the utilization of antenatal and delivery care services in Bangladesh: Where does the equity gap lie? BMC Pregnancy Childbirth. 2016 Dec; 16(1):1-6.

34. Wilunda C, Quaglio G, Putoto G, Takahashi R, Calia F, Abebe D, et al. Determinants of utilisation of antenatal care and skilled birth attendant at delivery in South West Shoa Zone, Ethiopia: A cross sectional study. Reprod Health. 2015 Dec; 12(1):1-12.

35. Link BG, Phelan JC, Miech R, Westin EL. The resources that matter: Fundamental social causes of health disparities and the challenge of intelligence. J Health Soc Behav. 2008 Mar; 49(1):72-91.

36. Starfield B, Shi L. The Medical Home, Access to Care, and Insurance: A Review of Evidence. Pediatrics. 2004 May 1; 113(Supplement 4):1493-8.

37. Ettner SL. The timing of preventive services for women and children: The effect of having a usual source of care. Am J Public Health. 1996 Dec; 86(12):1748-54.

38. Bengiamin MI, Capitman JA, Ruwe MB. Disparities in initiation and adherence to prenatal care: Impact of insurance, race-ethnicity and nativity. Matern Child Health J. 2010 Jul 1; 14(4):618-24.

39. Dey A, Hay K, Afroz B, Chandurkar D, Singh K, Dehingia N, et al. Understanding intersections of social determinants of maternal healthcare utilization in Uttar Pradesh, India. PLoS One. 2018 Oct 4; 13(10):e0204810.

40. Sridharan S, Pereira A, Hay K, Dey A, Chandurkar D, Veldhuizen S, et al. Heterogeneities in utilization of antenatal care in Uttar Pradesh, India: the need to contextualize interventions to individual contexts. Glob Health Action. 2018 Jan 1; 11(1):1517929.

41. Montagu D, Yamey G, Visconti A, Harding A, Yoong J. Where do poor women in developing countries give birth? a multi-country analysis of Demographic and health survey data. PLoS One. 2011 Feb 28; 6(2):e17155.

42. Uddin J, Pulok MH, Johnson RB, Rana J, Baker E. Association between child marriage and institutional delivery care services use in Bangladesh: intersections between education and place of residence. Public Health. 2019 Jun $1 ; 171: 6-14$. 
43. Situ KC, Neupane S. Women's Autonomy and Skilled Attendance During Pregnancy and Delivery in Nepal. Matern Child Health J. 2016 Jun; 20(6):1222-9.

44. Moyer CA, Mustafa A. Drivers and deterrents of facility delivery in sub-Saharan Africa: A systematic review. Reprod Health. 2013 Dec; 10(1):1-4.

45. Agha S, Carton TW. Determinants of institutional delivery in rural Jhang, Pakistan. Int J Equity Health. 2011 Dec; 10(1):1-12.

46. Tsegay Y, Gebrehiwot T, Goicolea I, Edin K, Lemma H, Sebastian MS. Determinants of antenatal and delivery care utilization in Tigray region, Ethiopia: A cross-sectional study. Int J Equity Health. 2013 Dec; 12(1):1-10.

\section{Figures}

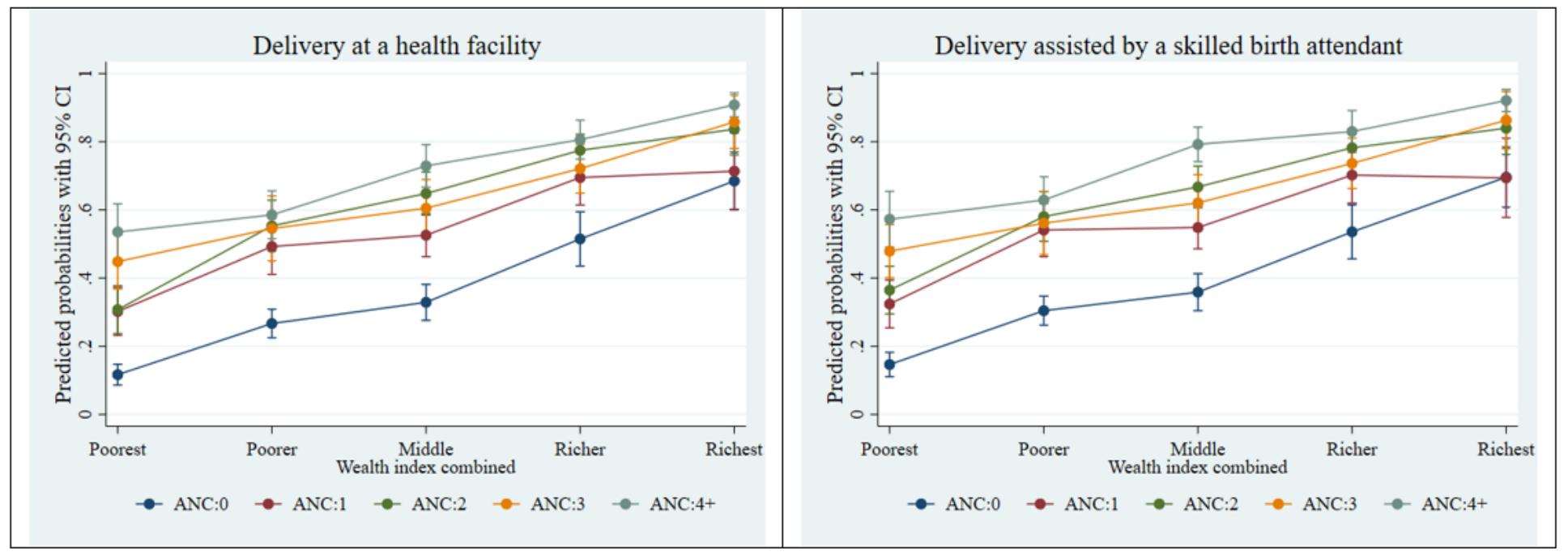

\section{Figure 1}

Adjusted predictions for institutional delivery care utilization by ANC visits by wealth index. Cl, confidence interval.
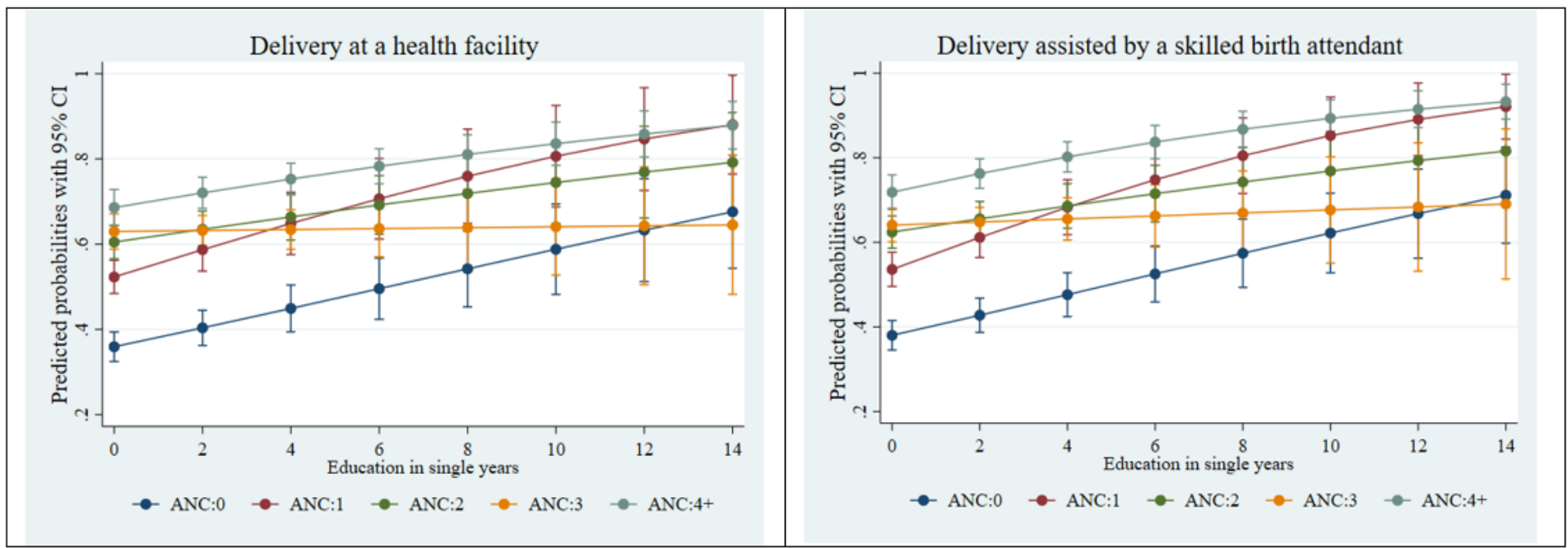

\section{Figure 2}

Adjusted predictions for institutional delivery care utilization by ANC visits by education. Cl, confidence interval. 


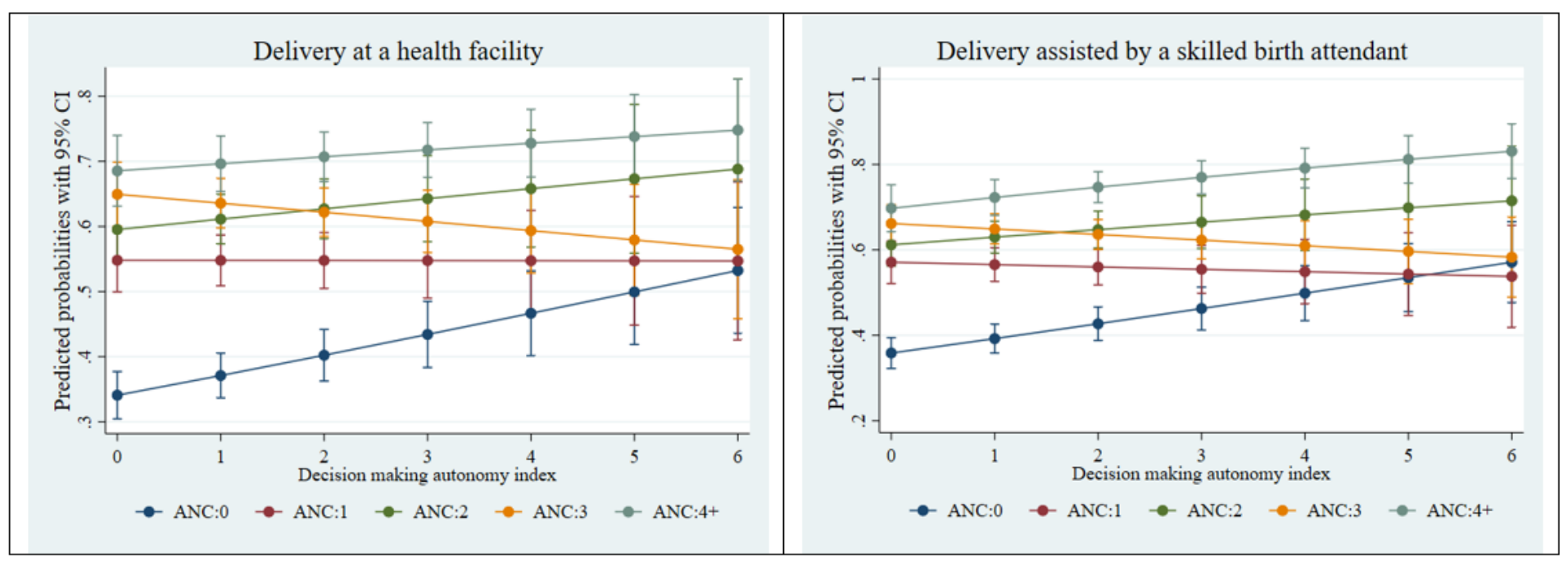

Figure 3

Adjusted predictions for institutional delivery care utilization by ANC visits by decision-making autonomy index. Cl, confidence interval.

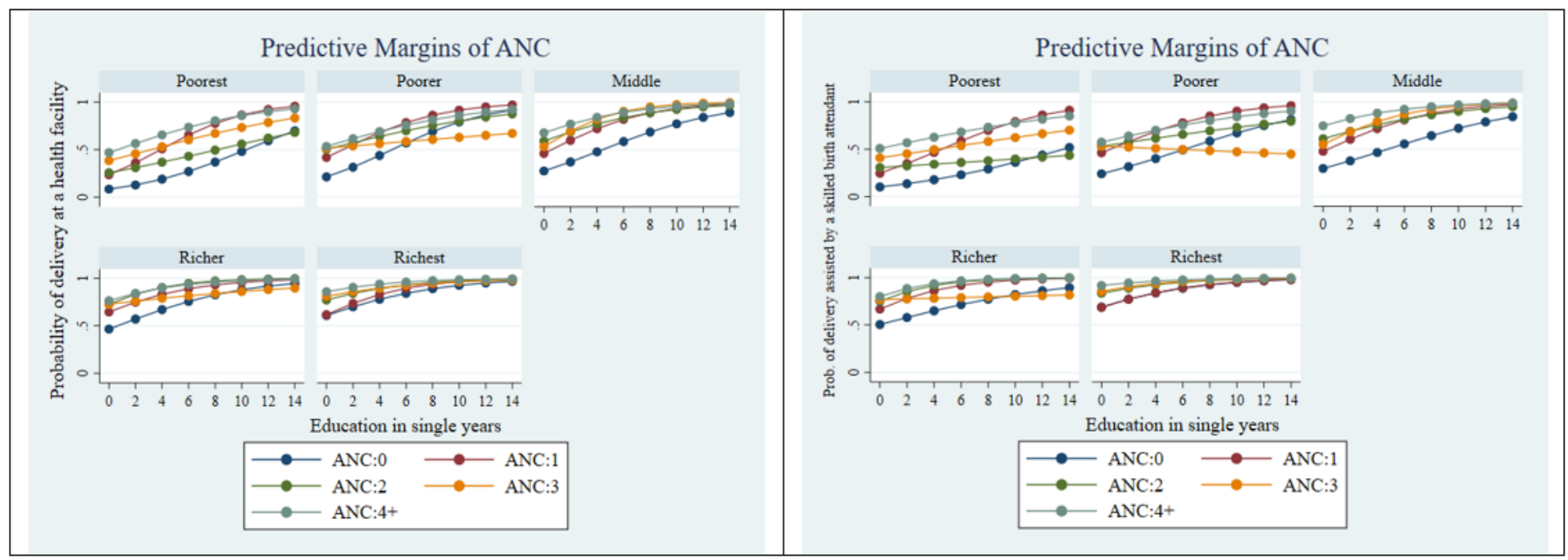

Figure 4

Adjusted predictions for institutional delivery care utilization by ANC visits by wealth index and education in years.

\section{Supplementary Files}

This is a list of supplementary files associated with this preprint. Click to download.

- Appendix.docx 